\section{Correspondence on 'Efficacy of a tight-control and treat-to-target strategy in axial spondyloarthritis: results of the open-label, pragmatic, cluster-randomised TICOSPA trial'}

We read with great interest the article by Molto et al. ${ }^{1}$ The authors conducted a pragmatic, cluster trial evaluating the efficacy and cost-effectiveness of a tight-control/treat-to-target (TC/T2T) strategy versus usual care (UC) over 48 weeks in 160 patients with axial spondyloarthritis (axSpA). The results showed that the percentage of patients achieving $\geq 30 \%$ improvement on the Axial SpondyloArthritis International Society-Health Index (the primary outcome) was not statistically significantly different between the two groups (TC/T2T vs UC: $47.3 \%$ vs $36.1 \%$, $\mathrm{p}=0.07)$. Despite this, 13 prespecified secondary outcomes performed better in the TC/T2T group at 48 weeks (5 of them reached statistical significance), and TC/T2T improved quality of life and reduced health-related cost compared with UC. This is an important trial showing the potential benefits of a $\mathrm{TC} /$ T2T strategy in clinical practice among patients with axSpA. However, there are some concerns that would better be clarified.

First, sample size calculation in this trial was based on a twostep method due to its cluster design, as indicated in the article. The designed sample size was 232 patients (116 per group), but only 160 patients (80 per group) were enrolled in the trial. The shortage of sample size was not discussed in the article throughout. While the primary outcome was not statistically significantly different between the two strategies, the authors acknowledged that this trial should not be simply interpreted as a negative trial and provided several good explanations for the lack of statistical significance. However, the main reason is more likely due to the much smaller sample size. Post-hoc conditional power analyses would help inform whether the trial was underpowered due to smaller sample size, had the study completed the preplanned enrolment size. ${ }^{2}$ Moreover, the 95\% CIs around the point estimates for the primary and secondary outcomes, which would have provided more informative results of the trial, have not been displayed in the article. Therefore, whether the results were truly statistically non-significant and clinically meaningless needs further discussion.

Second, contamination bias is almost unavoidable in pragmatic trials and thus needs to be carefully controlled. ${ }^{3}$ For this study, it might be helpful to report the proportion of rheumatologists in each centre who have readily provided healthcare similar to the TC/T2T strategy. Despite centres were randomised to allocate to either treatment group, there were only 18 centres and assumably simple randomisation was used. Indeed, baseline imbalances between the two groups were observed.

Third, for some continuous secondary outcome measures, the authors reported between-group difference at week 48 rather than change from week 0 to week 48 . It has been suggested in a clinical trial that analysis of change score with adjustment for baseline values of the outcome measure may be more appropriate, ${ }^{4}$ especially when there is a high correlation between baseline and follow-up measurements, which is generally the case in rheumatic diseases. ${ }^{5}$

We respect the significant contributions of the authors and look forward to the follow-up results and interpretations of this study.

\section{Guoqi Cai $\odot$, ${ }^{1}$ Xiaoqing Peng ${ }^{2}$}

${ }^{1}$ Department of Epidemiology and Biostatistics, School of Public Health, Anhui Medical University, Hefei, Anhui, China

${ }^{2}$ Department of Obstetrics and Gynaecology, First Affiliated Hospital of Anhui Medical University, Hefei, Anhui, China

Correspondence to Xiaoqing Peng, Department of Obstetrics and Gynaecology, First Affiliated Hospital of Anhui Medical University, Hefei, Anhui 230032, China; pengxiaoqing@ahmu.edu.cn

Contributors GC and XP contributed to study concept, writing and revision.

Funding This work was supported by the National Natural Science Foundation of China (grant number: 82000399).

Competing interests None declared.

Patient and public involvement Patients and/or the public were not involved in the design, or conduct, or reporting, or dissemination plans of this research.

Patient consent for publication Not required.

Provenance and peer review Not commissioned; internally peer reviewed.

(c) Author(s) (or their employer(s)) 2021. No commercial re-use. See rights and permissions. Published by BMJ.

\section{Check for updates}

To cite Cai G, Peng X. Ann Rheum Dis Epub ahead of print: [please include Day Month Year]. doi:10.1136/annrheumdis-2021-220904

Received 2 June 2021

Accepted 3 June 2021

\section{Linked}

http://dx.doi.org/10.1136/annrheumdis-2021-220913

Ann Rheum Dis 2021;0:1. doi:10.1136/annrheumdis-2021-220904

ORCID iD

Guoqi Cai http://orcid.org/0000-0002-6481-704X

\section{REFERENCES}

1 Molto A, López-Medina C, Van den Bosch FE, et al. Efficacy of a tight-control and treat-to-target strategy in axial spondyloarthritis: results of the open-label, pragmatic, cluster-randomised TICOSPA trial. Ann Rheum Dis 2021. doi:10.1136/ annrheumdis-2020-219585. [Epub ahead of print: 06 May 2021].

2 Cai G, Aitken D, Laslett LL, et al. Effect of intravenous zoledronic acid on Tibiofemoral cartilage volume among patients with knee osteoarthritis with bone marrow lesions: a randomized clinical trial. JAMA 2020;323:1456-66.

3 Robinson K, Allen F, Darby J, et al. Contamination in complex healthcare trials: the falls in care homes (finch) study experience. BMC Med Res Methodol 2020;20:46.

4 Vickers AJ, Altman DG. Statistics notes: analysing controlled trials with baseline and follow up measurements. BMJ 2001;323:1123-4.

5 Sokka T. Assessment of pain in rheumatic diseases. Clin Exp Rheumatol 2005;23:577-84. 